Article

\title{
Considerations on the Implications of the Internet of Things in Spanish Universities: The Usefulness Perceived by Professors
}

\author{
José-María Romero-Rodríguez $\mathbb{D}^{\mathbb{D}}$, Santiago Alonso-García ${ }^{\mathbb{D}}$, José-Antonio Marín-Marín \\ and Gerardo Gómez-García * (D) \\ Department of Didactics and School Organization, University of Granada, 18071 Granada, Spain; \\ romejo@ugr.es (J.-M.R.-R.); salonsog@ugr.es (S.A.-G.); jmarin@ugr.es (J.-A.M.-M.) \\ * Correspondence: gomezgarcia@ugr.es; Tel.: +34-958-246-687
}

Received: 28 June 2020; Accepted: 23 July 2020; Published: 24 July 2020

\begin{abstract}
Internet of Things (IoT) is an emerging technology in the field of education, which has not yet been consolidated. Acceptance and adoption studies of IoT in higher education are scarce. Accordingly, the purpose of this study was to explore the acceptance of the IoT by university professors for future adoption in higher education. An online survey was implemented based on the unified theory of acceptance and use of technology (UTAUT), in a sample of 587 Spanish university teachers, aged between 21 and 58. The results showed that performance expectancy, facilitating conditions, and attitude toward using technology were influential in behavioral intention to use IoT. While the intention for use was similar between men and women and with respect to age. However, in the different constructs of the UTAUT model, the highest average scores were obtained in men and in teachers over 36 years of age. Finally, the findings and implications of the paper are discussed, showing empirical evidence on the adoption and acceptance of IoT in higher education in the context of Spain, highlighting the need for further research on emerging technologies in a context that is marked by COVID-19.
\end{abstract}

Keywords: Internet of Things; innovative teaching practices; adoption factors; UTAUT; higher education; Spain

\section{Introduction}

The first two decades of the 21st century have witnessed unparalleled development in the field of communications and technology [1]. The globalization of commercial transactions, the flow of people and the rise of the well-known Information and Communication Technologies (ICT), has conceived a new relational paradigm of interaction between humans and objects $[2,3]$. In this sense, the current period in which we live can be classified according to various aspects.

On one hand, from the industrial development, placing us in the fourth revolution (from 2010 onwards) characterized by the so-called intelligent industry [4-6], where the decision making is autonomous by cyberphysical systems through the use of automatic learning and data analysis [7]. On the other, it can also be placed within the so-called fourth wave of computing, known as the Internet of Things (IoT) [8].

There is no doubt that the historical stage in which we are immersed is producing and will produce very significant changes for humanity. This technological period is characterised by new challenges for users that arise from the increase in the amount of data (Big Data) [9,10], from decisions taken automatically (artificial intelligence and robots) [11], from reduced visibility and greater ambiguity [12], and from greater risks to security and privacy (cybersecurity) $[13,14]$. In addition, there is the possibility 
that only a select group of the population will benefit, so it is important to study this stage from a perspective of digital inequality, where the digital divide means differences between the population that has access to the Internet and those that cannot connect to it at home. The IoT, the International Telecommunication Union (ITU) [15] defines it as "a global infrastructure for the information society, enabling advanced services by interconnecting (physical and virtual) things based on existing and evolving interoperable information and communication technologies". In this sense, Ashton [16] coined the term "Internet of Things", to describe the network connecting objects in the physical world to the Internet [17]. The idea behind this concept is that, every day, physical devices in our homes, businesses, or educational centers [18,19], connect through the Internet with virtual servers and perform interactions generating a huge amount of information. These devices, such as temperature probes, geolocators, cameras, movement sensors, pressure sensors, etc., have the capacity to be programmed and to interact with them from any part of the world, without the need to resort to presence for their operation [11]. The joint use of these devices can enable much more complex applications, such as the development of smart appliances, smart vehicles, and smart homes with automation systems, as well as facility management and safety systems [12], all of which have a high impact in areas, such as medicine and health, transport, construction, agriculture, and industrial applications [20]. In the case of education, the literature reviewed $[18,19,21-27]$ suggests that the impact of IoT today is less than in other sectors.

In particular, IoT technology in education has a greater impact on Higher Education than in other educational stages. This is due to the fact that the characteristics of higher studies and educational institutions are more open and favorable to innovation and the incorporation of technologies for both teaching and research [22]. IoT technology in Higher Education has the potential to clearly impact on how education systems are re-imagined and redesigned, from a traditional system to one that is scalable, adaptable, flexible, and more adaptive to dynamic and rapid changes [28]. Similarly, in the logistics of educational management and the design of learning, facilities can be more responsive to the learning needs of students. As well as the reconstitution of training delivery systems, previous studies show that, for this technology to become a reality in higher education, attitudes towards IoT and material access. So, that educational and income differences, need to be taken into account and not generate inequalities and therefore a possible rejection of its implementation [3]. Another factor that affects its dissemination is the level of training. Thus, people with higher education, like those with higher incomes, have more positive attitudes and are the first to actually buy IoT technology [29]. This also means that they are the first to develop the necessary skills and engage in diverse use of IoT [30].

Among the potential benefits that IoT can offer to education are improved campus security, efficient facility energy systems, customized training plans accessible at any time in a ubiquitous and context-aware learning environment [31], improved student performance and increased accountability through data collection and subsequent analysis to find more efficient ways of teaching and learning [32]. The use of this technology provides deeper learning experiences, as it changes the way that we all learn and engage in learning activities, allowing for students to participate in their own learning and content creation and helping teachers to deliver personalized content that improves student outcomes [26].

Likewise, the implementation of IoT in universities offers opportunities and challenges. The technologies implied by IoT promote the development of an IoT society and the promotion of a new digital culture, where the opportunities to obtain online degrees and easy access to learning content in both structured and unstructured formats are pushing higher education institutions to make a digital turnaround that represents a drastic change in the traditional educational paradigm [25]. The challenges include the need for access to training content on demand at any time, the use and development of mobile applications for teaching and learning [33], ensuring the security of devices, services and the privacy of the IoT ecosystem [34], ensuring the quality of training and assessment of students, and, finally, seeking alternative strategies and resources to maintain the high cost of maintaining the IoT technology itself [35]. Based on these ideas, the purpose of this study was to 
explore the acceptance of the IoT by university professors for future adoption in higher education. The following research question was followed:

RQ: Do the factors of the UTAUT model influence the acceptance of the IoT in higher education?

\section{Theoretical Background and Hypotheses Development}

The unified theory of acceptance and use of technology (UTAUT) has been applied, since it is the main methodological framework for knowing the intention to use a certain technology [36-42]. This model was developed by Venkatesh et al. [43] to explain the behavior and predisposition of users to use the technology. The main factors of the UTAUT model have been extracted from eight different theoretical frameworks that make up the central constructions of the model: performance expectancy, effort expectancy, facilitating conditions, and social influence [43,44]. In this study, the different constructs were adapted to the IoT. Therefore, all of the dimensions were adequately contextualized with the central topic of the research.

The research model was composed of the constructions of the UTAUT: performance expectancy (PE), effort expectancy (EE), social influence (SI), facilitating conditions (FC), attitude toward using technology (ATUT), and behavioral intention to use (BI). In the established hypothetical model, BI is affected by PE, EE, SI, FC, and ATUT. While gender and age affect PE, EE, SI, FC, and ATUT (Figure 1).

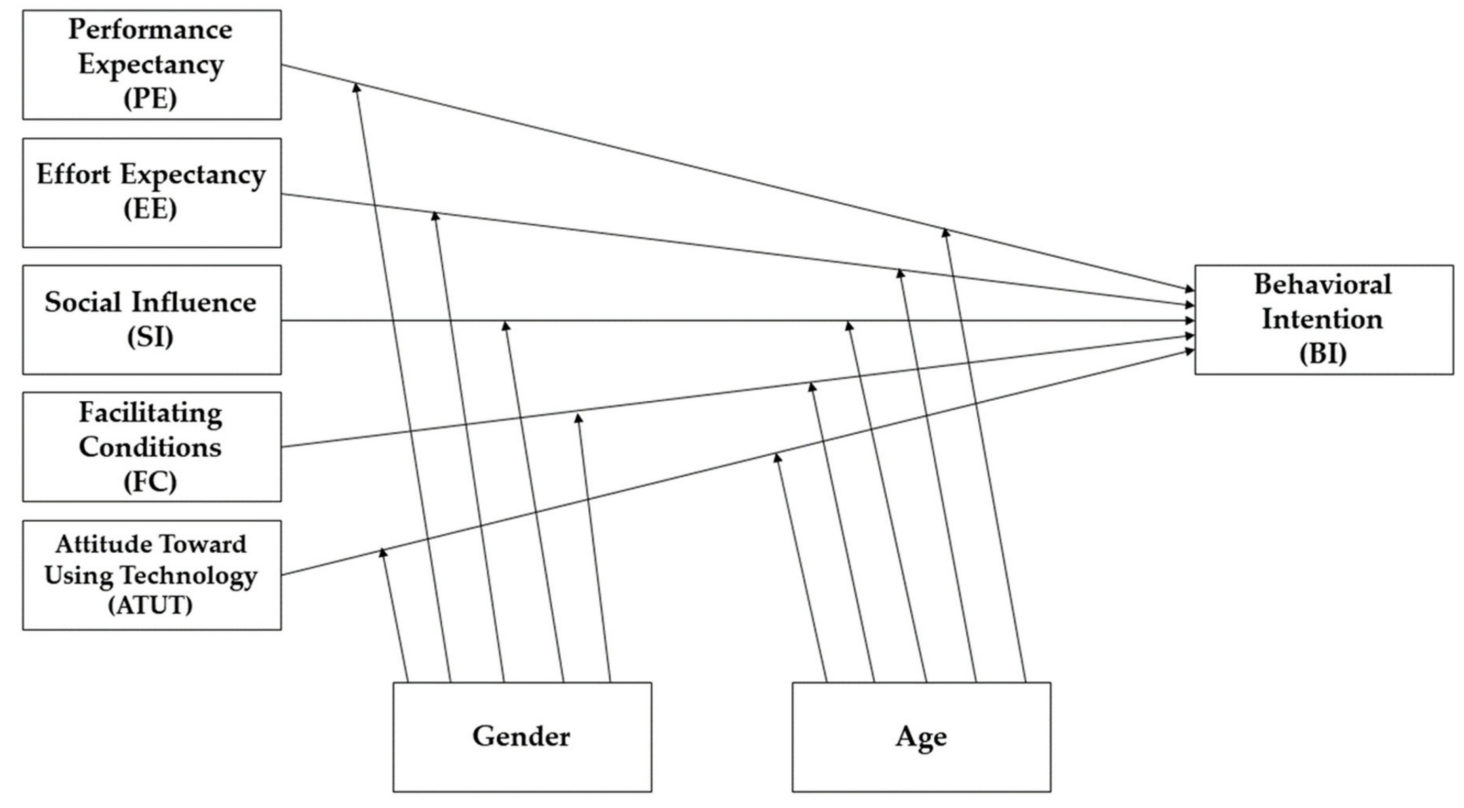

Figure 1. Research model.

\subsection{Performance Expectancy (PE)}

Several studies conclude that PE significantly influences the intention to use a certain technology $[37,45,46]$. In particular, performance expectancy is defined as "the degree to which an individual believes that using the system will help him or her to attain gains in job performance" [43]. In the context of research, performance expectancy relates to the improvement of job performance. They were proposed as hypotheses:

Hypothesis 1 (H1): Performance expectancy has a significant effect on behavioral intention to use IoT.

Hypothesis 2 (H2): Gender is a factor that has a significant effect on performance expectancy of IoT.

Hypothesis 3 (H3): Age is a factor that has a significant effect on performance expectancy of IoT. 


\subsection{Effort Expectancy (EE)}

This construct has shown in previous studies to have a significant impact on the intention to use a certain technology $[36,47,48]$. In particular, effort expectancy is defined as "the degree of ease associated with the use of the system" [43]. In the context of the research, effort expectancy was related to the ease of use of the IOT by teachers. They were proposed as hypotheses:

Hypothesis 4 (H4): Effort expectancy has a significant effect on behavioral intention to use IoT.

Hypothesis 5 (H5): Gender is a factor that has a significant effect on effort expectancy of IoT.

Hypothesis 6 (H6): Age is a factor that has a significant effect on effort expectancy of IoT.

\subsection{Social Influence (SI)}

This construct has shown in previous studies a significant influence on the intention to use certain technologies [49-51]. Social influence is defined as the "degree to which an individual perceives that important others believe he or she should use the new system" [43]. In the context of research, social influence refers to the opinion of other teachers, friends and family about the use of IoT. They were proposed as hypotheses:

Hypothesis 7 (H7): Social influence has a significant effect on behavioral intention to use IoT.

Hypothesis 8 (H8): Gender is a factor that has a significant effect on social influence of IoT.

Hypothesis 9 (H9): Age is a factor that has a significant effect on social influence of IoT.

\subsection{Facilitating Conditions ( $F C$ )}

This construct has been related as an influential factor in the intention to use a certain technology [52-54]. In particular, facilitating conditions are defined as the "degree to which an individual believes that an organizational and technical infrastructure exists to support use of the system" [43]. In the research context, facilitating conditions was related to the human, organizational, and technical support for using the IO. They were proposed as hypotheses:

Hypothesis 10 (H10): Facilitating conditions has a significant effect on behavioral intention to use IoT.

Hypothesis 11 (H11): Gender is a factor that has a significant effect on facilitating conditions of IoT.

Hypothesis 12 (H12): Age is a factor that has a significant effect on facilitating conditions of IoT.

\subsection{Attitude Toward Using Technology (ATUT)}

This construct has been linked to the intention of use in several studies [44,55,56]. In particular, attitude toward using technology is defined as "an individual's overall affective reaction to using a system" [43]. In the research context, attitude toward using technology refers to the predisposition of teachers to use IoT in their teaching activities. They were proposed as hypotheses:

Hypothesis 13 (H13): Attitude toward using technology has a significant effect on behavioral intention to use IoT.

Hypothesis 14 (H14): Gender is a factor that has a significant effect on attitude toward using technology of IoT. 
Hypothesis 15 (H15): Age is a factor that has a significant effect on attitude toward using technology of IoT.

\section{Method}

\subsection{Participants and Procedure}

We adopted a cross-sectional study design by applying an online questionnaire to a total of 587 Spanish university teachers of Educational Sciences. The research used a convenience sampling. Thus, the participants were invited to participate in the survey via e-mail, where information was provided regarding the purpose of the study and the anonymous processing of the data. By conducting the survey, all participants gave their informed consent. The data collection period took place during the month of March 2020.

The sample of university professors was composed of 162 men (27.6\%) and 425 women $(72.4 \%)$, aged between 21 and 58 years $(M=35.18 ; S D=6.97)$. The World Health Organization division was used to establish the age ranges [57]. Thus, in the 21-35 year age group, corresponding to young adults, there were 215 teachers $(36.6 \%$ ) and, in the $\geq 36$ age group, corresponding to older adults, there were 372 teachers $(63.4 \%)$.

\subsection{Measures}

The items that made up the constructs of the UTAUT model were telematically applied through a self-reporting questionnaire. The dimensions performance expectancy (PE), effort expectancy (EE), social influence (SI), facilitating conditions (FC), attitude toward using technology (ATUT), and behavioral intention to use (BI) [43], were adapted to the specific technology IoT. The response mode of the scale followed that of the UTAUT models, based on a seven-level Likert scale $(1=$ strongly disagree to $7=$ strongly agree) $[58,59]$. In the case of UTAUT models, psychometric properties are calculated in all studies, which have a uniform premise regarding the adequacy of psychometric properties and internal consistency [36-42]. Data regarding validity and reliability were collected in results section.

\subsection{Data Analysis}

Statistical tests were used $t$-test to check for significant differences between two populations, convergent and discriminant validity and structural equation modeling (SEM). Convergent validity and discriminant validity were calculated to establish the adequacy in the psychometric properties of the instrument. The measurement model [60] was used for this purpose.

On the other hand, the structural equation model (SEM) was carried out for the contrast of hypotheses, since it allowed to observe the interrelations between the constructions [61]. It was an indispensable condition for establishing the SEM to check the hypothesis of multivariate normality of the data, which was confirmed by the Mardia coefficient [62]. The model's goodness-of-fit indexes were also calculated. Finally, the constructions and suitability of the model were checked by means of path analysis.

The data were analyzed with the statistical packages IBM SPSS and IBM SPSS Amos, version 24 (IBM Corp., Armonk, NY, USA).

\section{Results}

Based on the means, standard deviations, and differences based on gender, certain distinctions were found in the adoption of the IoT by men and women (Table 1). Men obtained higher scores in all the constructs of the UTAUT model. However, these differences were only significant in EE $(p=0.020)$, FC $(p=0.002)$, and ATUT $(p=0.005)$. 
Table 1. Mean and standard deviation of scores by scale and differences based on gender.

\begin{tabular}{cccccccc}
\hline \multirow{2}{*}{ Construct } & \multicolumn{3}{c}{ Men } & \multicolumn{2}{c}{ Women } & \multirow{2}{*}{$\boldsymbol{t}$} & $\boldsymbol{p}$ \\
\cline { 2 - 6 } & $\mathbf{M}$ & SD & $\mathbf{M}$ & SD & & & \\
\hline PE & 18.64 & 6.532 & 17.98 & 6.480 & 1.088 & 585 & 0.277 \\
EE & 20.56 & 5.660 & 19.28 & 6.078 & 2.327 & 585 & 0.020 \\
SI & 17.85 & 6.980 & 17.32 & 6.902 & 0.826 & 585 & 0.409 \\
FC & 17.77 & 5.390 & 16.27 & 5.207 & 3.079 & 585 & 0.002 \\
ATUT & 21.17 & 5.524 & 19.68 & 5.843 & 2.808 & 585 & 0.005 \\
BI & 16.63 & 5.156 & 16.04 & 5.143 & 1.251 & 585 & 0.212 \\
\hline \multicolumn{7}{c}{ Note: $d f=$ degrees of freedom. }
\end{tabular}

On the other hand, means, standard deviations, and differences based on age also showed certain distinctions (Table 2). The age group over 36 years obtained the highest mean scores in almost all constructs (EE, PE, SI, and ATUT). While teachers in the 21-35 age range only excelled in FC and BI. Significant differences were established in the PE $(p=0.031)$ and EE $(p=0.020)$ constructs. Thus, the degree of acceptance of university professors was above 16 on average, in terms of gender and age. Taking into account that the BI scores range from 1 to 21 , the value is high. Furthermore, the scores obtained by the teachers in the value $16,17,18,19,20$, and 21 add up to $62.5 \%$ of responses, corresponding to a high acceptance of the IoT.

Table 2. Mean and standard deviation of scores by scale and differences based on age.

\begin{tabular}{cccccccc}
\hline \multirow{2}{*}{ Construct } & \multicolumn{2}{c}{$21-35$} & \multicolumn{2}{c}{$\geq \mathbf{3 6}$} & \multirow{2}{*}{$\boldsymbol{d} f$} & $\boldsymbol{p}$ \\
\cline { 2 - 6 } & $\mathbf{M}$ & SD & $\mathbf{M}$ & SD & & & \\
\hline PE & 17.40 & 6.608 & 18.60 & 6.397 & -1.697 & 551 & 0.031 \\
EE & 18.88 & 6.132 & 20.07 & 5.867 & -2.083 & 551 & 0.020 \\
SI & 17.23 & 7.026 & 17.60 & 6.866 & -0.242 & 551 & 0.540 \\
FC & 17.06 & 5.091 & 16.47 & 5.406 & 1.545 & 551 & 0.190 \\
ATUT & 20 & 5.876 & 20.15 & 5.748 & -0.366 & 551 & 0.759 \\
BI & 16.27 & 5.103 & 16.16 & 5.182 & 0.322 & 551 & 0.814 \\
\hline \multicolumn{7}{c}{ Note: $d f=$ degrees of freedom. }
\end{tabular}

Regarding convergent validity and reliability of the instrument, the composite reliability (CR) values of the constructs were above 0.8 and the average variance extracted (AVE) was above 0.5 in all of them [60] (Table 3). The reliability values of Cronbach's alpha coefficient were acceptable in all constructs [63], with the majority being above 0.8 and an overall reliability of 0.946 .

In discriminant validity analysis, the square root of AVE was taken to correlate the latent constructs (Table 4). It was found that each factor represented a different dimension, so the psychometric characteristics of the instrument were acceptable [64]. Therefore, factor loads were adequate and the instrument was found to have strong convergent and discriminant validity [65]. 
Table 3. Convergent validity measures and reliability.

\begin{tabular}{|c|c|c|c|c|c|c|}
\hline Construct & Item & $\begin{array}{l}\text { Factor } \\
\text { Loading }\end{array}$ & CR & AVE & $\alpha$ & Global $\alpha$ \\
\hline \multirow{4}{*}{ PE } & PE1 & 0.837 & \multirow{4}{*}{0.926} & \multirow{4}{*}{0.758} & \multirow{4}{*}{0.939} & \\
\hline & PE2 & 0.863 & & & & \\
\hline & PE3 & 0.886 & & & & \\
\hline & PE4 & 0.896 & & & & \\
\hline \multirow{4}{*}{ EE } & EE1 & 0.792 & \multirow{4}{*}{0.897} & \multirow{4}{*}{0.687} & \multirow{4}{*}{0.909} & \\
\hline & EE2 & 0.816 & & & & \\
\hline & EE3 & 0.850 & & & & \\
\hline & EE4 & 0.856 & & & & \\
\hline \multirow{4}{*}{ SI } & SI1 & 0.863 & \multirow{4}{*}{0.919} & \multirow{4}{*}{0.740} & \multirow{4}{*}{0.927} & \\
\hline & SI2 & 0.865 & & & & \\
\hline & SI3 & 0.811 & & & & 0.946 \\
\hline & SI4 & 0.901 & & & & \\
\hline \multirow{4}{*}{$\mathrm{FC}$} & FC1 & 0.688 & \multirow{4}{*}{0.838} & \multirow{4}{*}{0.565} & \multirow{4}{*}{0.734} & \\
\hline & FC2 & 0.734 & & & & \\
\hline & FC3 & 0.820 & & & & \\
\hline & FC4 & 0.761 & & & & \\
\hline \multirow{4}{*}{ ATUT } & ATUT1 & 0.728 & \multirow{4}{*}{0.802} & \multirow{4}{*}{0.510} & \multirow{4}{*}{0.805} & \\
\hline & ATUT2 & 0.850 & & & & \\
\hline & ATUT3 & 0.715 & & & & \\
\hline & ATUT4 & 0.528 & & & & \\
\hline \multirow{3}{*}{ BI } & BI1 & 0.929 & \multirow{3}{*}{0.957} & \multirow{3}{*}{0.881} & \multirow{3}{*}{0.946} & \\
\hline & $\mathrm{BI} 2$ & 0.935 & & & & \\
\hline & $\mathrm{BI} 3$ & 0.953 & & & & \\
\hline
\end{tabular}

Table 4. Discriminant validity measures.

\begin{tabular}{ccccccc}
\hline & PE & EE & SI & FC & ATUT & BI \\
\hline PE & $\mathbf{0 . 8 7 0}$ & & & & & \\
EE & 0.660 & $\mathbf{0 . 8 2 8}$ & & & & \\
SI & 0.903 & 0.711 & $\mathbf{0 . 8 6 0}$ & & & \\
FC & 0.621 & 0.494 & 0.696 & $\mathbf{0 . 7 5 2}$ & $\mathbf{0 . 7 1 4}$ & $\mathbf{0 . 9 3 9}$ \\
ATUT & 0.501 & 0.750 & 0.568 & 0.433 & 0.532 & 0.352 \\
BI & 0.402 & 0.398 & 0.404 & & \\
\hline
\end{tabular}

Note: Diagonals represent the average variance extracted, while the other matrix entries represent the squared correlations.

With regard to the establishment of the SEM, the hypothesis of multivariate data normality was confirmed. To do this, it was necessary for the value obtained in the Mardia coefficient to be below $p^{*}(p+2)$ [66], where $p$ corresponded to 23, with this being the total number of variables in the scale. Likewise, the value of the Mardia coefficient was 158,341, less than 575.

The model's goodness-of-fit indices, on the other hand, were well matched to the data: Chi-square $\left(\chi^{2}=0.564\right)$; degrees of freedom $(d f=2)$; the ratio $\chi^{2} / d f$ was 0.282 ; goodness-of-fit index $(\mathrm{GFI}=1)$; square-root mean square approximation error $($ RMSEA $=0.000)$; normalized fit index $(\mathrm{NFI}=1)$; comparative fit index (CFI = 1.000); and, adjusted goodness-of-fit index (AGFI $=0.996)$.

The contrast of hypotheses through the path analysis gathered the support of seven hypotheses out of the 15 initially established, the hypotheses that were not supported were rejected (Table 5). The relationships that supported the hypothesis about having a significant and positive effect on behavioral intention to use IoT were: performance expectancy (H1), facilitating conditions (H10), and attitude toward using technology (H13). Gender had a significant and negative effect on facilitating conditions (H11), and attitude toward using technology (H14). Additionally, age had a significant and positive effect on performance expectancy (H3) and effort expectancy (H6). 
Table 5. Hypothesis testing results.

\begin{tabular}{|c|c|c|c|c|c|}
\hline Hypothesis & Relationship & Path Coefficient & CR & $p$ & Results \\
\hline $\mathrm{H} 1$ & $\mathrm{PE} \rightarrow \mathrm{BI}$ & 0.175 & 2.688 & 0.007 & Supported \\
\hline $\mathrm{H} 2$ & $\mathrm{PE} \leftarrow$ Gender & -0.026 & -0.628 & 0.530 & Rejected \\
\hline H3 & $\mathrm{PE} \leftarrow$ Age & 0.114 & 2.731 & 0.006 & Supported \\
\hline $\mathrm{H} 4$ & $\mathrm{EE} \rightarrow \mathrm{BI}$ & -0.013 & -0.235 & 0.814 & Rejected \\
\hline H5 & $\mathrm{EE} \leftarrow$ Gender & -0.080 & -1.936 & 0.053 & Rejected \\
\hline H6 & $\mathrm{EE} \leftarrow$ Age & 0.093 & 2.234 & 0.026 & Supported \\
\hline $\mathrm{H} 7$ & $\mathrm{SI} \rightarrow \mathrm{BI}$ & -0.071 & -1.015 & 0.310 & Rejected \\
\hline $\mathrm{H} 8$ & $\mathrm{SI} \leftarrow$ Gender & -0.026 & -0.616 & 0.538 & Rejected \\
\hline H9 & $\mathrm{SI} \leftarrow$ Age & 0.051 & 1.211 & 0.226 & Rejected \\
\hline H10 & $\mathrm{FC} \rightarrow \mathrm{BI}$ & 0.218 & 5.228 & $* * *$ & Supported \\
\hline H11 & $\mathrm{FC} \leftarrow$ Gender & -0.135 & -3.245 & 0.001 & Supported \\
\hline H12 & $\mathrm{FC} \leftarrow$ Age & -0.051 & -1.219 & 0.223 & Rejected \\
\hline H13 & $\mathrm{ATUT} \rightarrow \mathrm{BI}$ & 0.376 & 8.214 & $* * *$ & Supported \\
\hline H14 & $\begin{array}{l}\text { ATUT } \leftarrow \\
\text { Gender }\end{array}$ & -0.118 & -2.826 & 0.005 & Supported \\
\hline H15 & ATUT $\leftarrow$ Age & -0.014 & -0.325 & 0.745 & Rejected \\
\hline
\end{tabular}

Note: $\mathrm{CR}=$ critical radio; ${ }^{* * *}$ Significant at $p<0.001$.

In the SEM, only the values of significant effects were collected, while the non-significant relations were shown with broken lines to facilitate their interpretation (Figure 2). Thus, the trajectory coefficients of H1, H3, H6, H10, H11, H13, and H14 are shown. Of the total constructs of the UTAUT model, effort expectancy and social influence did not influence the behavioral intention to use IoT. The model determination coefficients $\left(R^{2}\right)$ for each construct were for $\mathrm{PE}\left(R^{2}=0.015\right)$; $\mathrm{EE}\left(R^{2}=0.018\right)$; $\mathrm{SI}\left(R^{2}=0.004\right)$; FC $\left(R^{2}=0.018\right) ; \operatorname{ATUT}\left(R^{2}=0.013\right) ;$ and, BI $\left(R^{2}=0.325\right)$.

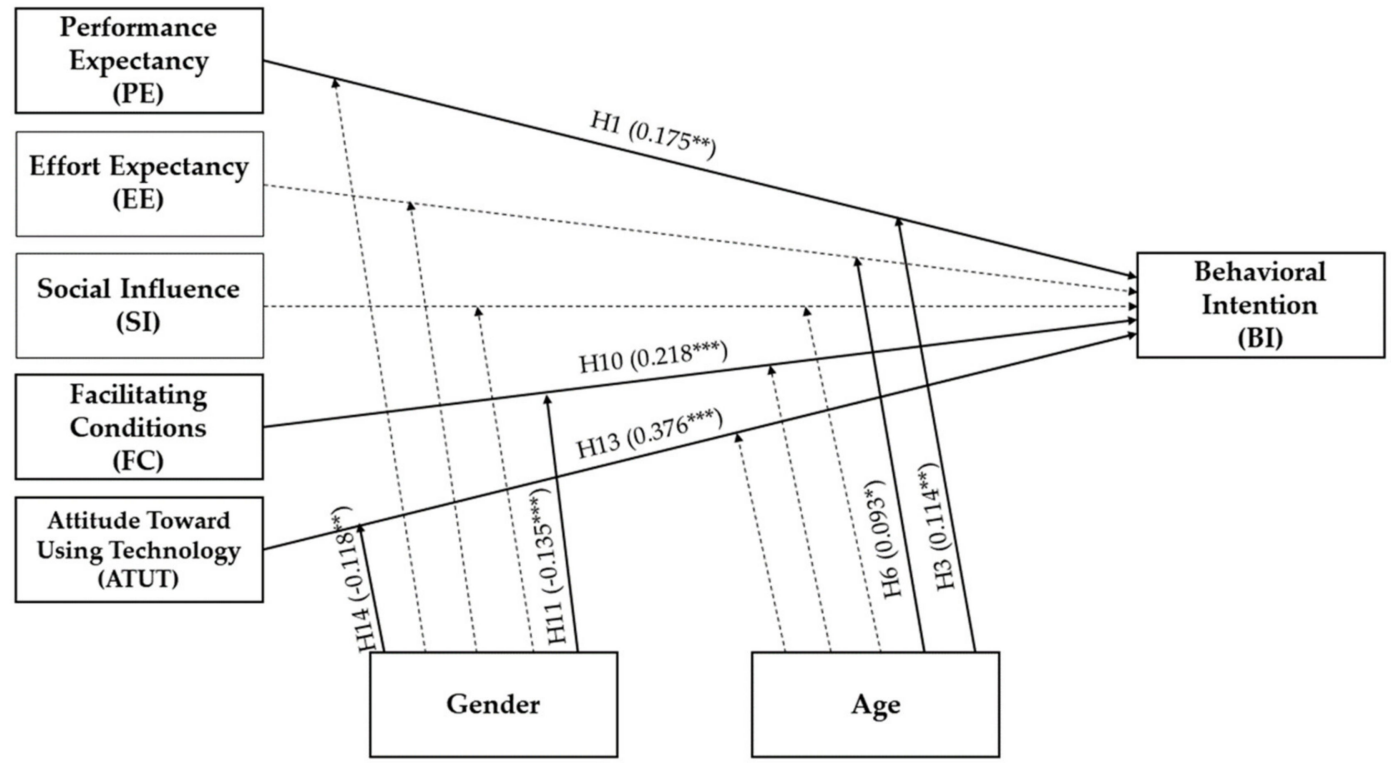

Figure 2. Structural measurement model. Note: ${ }^{*}$ Significant at $p<0.05 ;{ }^{*}$ Significant at $p<0.01$; *** Significant at $p<0.001$.

Finally, the results indicated differences according to gender and age. At the same time, significant constructs were found in the intention of use IoT by university professors. 


\section{Discussion}

The process of adoption of a specific type of technology takes place when there is a degree of harmony between various factors that have an impact on human behavior. It is a complex process that involves personal, interpersonal, and social factors that directly influence whether a particular subject interacts with the technological device [37,39].

Based on this idea, the present work determined as a fundamental objective to study which factors influence the degree of acceptance of IoT in Higher Education teachers. To do so, it was framed in the conceptual bases established by the UTAUT model in terms of socio-demographic variables that participate in this decision process. Thus, the predictive power of the model was $43 \%$ of the variance, which was adequate, while taking into account that in most of the researches that have applied this model have reached values between $20 \%$ and $70 \%$ [38].

The main findings of the research determined that, on the basis of gender, men scored higher overall than women. In addition, through the $t$ test the differences presented in EE, FC, and ATUT were found to be significant. In this sense, a line is established that coincides with other studies in the scientific literature that have applied the UTAUT model and in which gender was presented as an influential factor [37]. Therefore, the constructs that received the highest scores were EE and ATUT, parameters that are associated with intrapersonal perception in attitudinal and competency terms towards the technological device, results previously obtained in previous UTAUT models [12,28]. In other words, higher education teachers show a positive predisposition towards the use of IoT, as well as confidence that they can correctly interact with this type of technology and extract optimum performance from it.

The results showed that teachers aged 36 and older had higher scores in UTAUT model (except FC) than those who were younger. The $t$-test found that those differences were significant for PE and EE. This finding is surprising, as it undoubtedly shows a sense of change in the multiple studies that determine how there is a direct correlation between age and the attitude and predisposition to use technology, as well as the belief in the difficulty of using it [35]. Accordingly, it changes the trend highlighted in previous studies, where the fact of being younger has been associated with having a greater predisposition towards the use of technology.

On the other hand, the configuration of the UTAUT model through the path analysis showed how seven hypotheses out of the 15 proposed at the beginning of the research were supported by the obtained results. Firstly, with respect to PE, it was shown that it directly influenced behavioral intention (H1), as indicated by previous research using this same type of model [36,37]. It is, therefore, essential that teachers perceive the usefulness and the many educational opportunities that reside in IoT in order to make use of it in the future. Likewise, age was presented as a significant factor affecting PE and EE (H3, H6). Similarly, FC is presented as a powerful factor affecting the behavioral intention to use IoT (H10). Thus, the idea is established that the use of IoT will be greater by teachers if there is a technical infrastructure that supports the use of IoT. Therefore, it will be essential that when using IoT in universities, the relevant channels and tools are available to guarantee optimum use of the technology. In relation to this same construct, the model made it possible to know that gender has a significant effect on FC (H11). Finally, it allowed extracting that ATUT has a significant effect in behavioral intention to use IoT and that the gender factor is determinant in presenting a greater predisposition of use or not.

In contrast, the remaining construct of the model, SI, did not present any significance in the model and, therefore, it can be stated that they do not present any significance when it comes to influencing the adoption of IoT in this study. These results do not correspond to previous studies in which SI was postulated as a powerful predictor in the adoption towards the technological device [43,51].

The limitations of this work are found in the limited use of the constructs, where, in future studies, it would be possible to incorporate other constructs for the UTAUT model, such as the experience of the teaching staff with IoT or the willingness to use a certain technology. However, only the gender and age variables were chosen, because the insertion of more external variables would have lowered the 
predictive power of the model. On the other hand, in terms of prospective study in this sense, it can establish the focus on the analysis of the adoption of different types of technology that are bursting into today's society and, therefore, into the education system. An example of this is the case of artificial intelligence, an area that is destined to occupy the educational reality in the coming years.

\section{Conclusions}

In recent years technology has brought about changes in society at a dizzying rate. This has caused the education system to mark as a challenge the immersion of new resources that have burst into the classrooms, promoting a change in how we understood teaching until now. Specifically, the appearance of IoT has promoted a new range of teaching possibilities that the university must take into account in its educational plans.

For this reason, the aim of this study was to find the degree of acceptance of IoT among Spanish university teachers. The findings obtained in the research showed that the participants present a high degree of acceptance to IoT (with averages above value 16 in a range of 1 to 21 ), as well as an acceptable predisposition to its future use. This translates into a percentage of $62.5 \%$ of university teachers of Educational Sciences. Therefore, we are in a new scenario for the educational system and its professionals, so it is necessary that the institutions bet on the immersion of these resources in the universities, as well as to promote a digital training in the teachers that predicts innovation and improvement of educational pragmatics. Here lies the main contribution of this paper, which acts as a testing of the situation of IoT in university education in a context that is marked by the COVID-19 pandemic, where virtual and training processes through virtual platforms are marking the way of learning.

In conclusion, we must continue on a path of work that gradually manages to mitigate the existing resistance to the use of technology in university classrooms. In this case, IoT is considered to be one of the main drivers of the so-called industry 4.0 and the transformation of companies and institutions. Therefore, from the educational context, we must favor this position through quality training in this area, as well as the adoption of this type of emerging resources in the classroom, with the aim of making universities a space in which the configuration of innovative learning ecosystems takes place, promoting dynamic citizens who are up to date with the demands and needs that are presented by society today.

Author Contributions: Conceptualization, J.-M.R.-R., and S.A.-G.; methodology, J.-A.M.-M., and G.G.-G.; software, G.G.-G.; formal analysis, J.-M.R.-R.; investigation, S.A.-G., and J.-A.M.-M.; writing—original draft preparation, S.A.-G., G.G.-G., and J.-M.R.-R.; writing-review and editing, S.A.-G.; J.-A.M.-M., and G.G.-G.; visualization, J.-A.M.-M.; supervision, J.-M.R.-R. All authors have read and agreed to the published version of the manuscript.

Funding: I+D+I Project Research of Results Transfer Office (OTRI) of the University of Granada (Reference: CNT4315).

Acknowledgments: To the researchers of the research group AREA (HUM-672) of the University of Granada.

Conflicts of Interest: The authors declare no conflict of interest.

\section{References}

1. Waghid, Y.; Waghid, Z.; Waghid, F. The fourth industrial revolution reconsidered: On advancing cosmopolitan education. South Afr. J. High. Educ. 2019, 33. [CrossRef]

2. Schmidt, E.; Cohen, J. The New Digital Age: Transforming Nations, Businesses, and Our Lives; Vintage: London, UK, 2014.

3. Van Deursen, A.; van der Zeeuw, A.; de Boer, P.; Jansen, G.; van Rompay, T. Digital inequalities in the internet of things: Differences in attitudes, material access, skills, and usage. Inf. Commun. Soc. 2019, 1-19. [CrossRef]

4. Kusiak, A. Smart manufacturing. Int. J. Prod. Res. 2017, 56, 508-517. [CrossRef]

5. Negri, E.; Fumagalli, L.; Macchi, M. A Review of the roles of digital twin in CPS-based production systems. Procedia Manuf. 2017, 11, 939-948. [CrossRef] 
6. Tao, F.; Qi, Q.; Wang, L.; Nee, A. Digital twins and cyber-physical systems toward smart manufacturing and industry 4.0: Correlation and comparison. Engineering 2019, 5, 653-661. [CrossRef]

7. Lee, J.; Bagheri, B.; Kao, H. A cyber-physical systems architecture for industry 4.0-based manufacturing systems. Manuf. Lett. 2015, 3, 18-23. [CrossRef]

8. Asseo, I.; Johnson, M.; Nilsson, B.; Chalapathy, N.; Costello, T. Riding the wave in higher education. Educ. Rev. 2016, 51, 10-31.

9. Marín-Marín, J.; López-Belmonte, J.; Fernández-Campoy, J.; Romero-Rodríguez, J. Big data in education. A bibliometric review. Soc. Sci. 2019, 8, 223. [CrossRef]

10. Lee, J.; Kao, H.; Yang, S. Service Innovation and Smart Analytics for Industry 4.0 and Big Data Environment. Procedia Cirp 2014, 16, 3-8. [CrossRef]

11. Bansal, S.; Kumar, D. IoT ecosystem: A survey on devices, gateways, operating systems, middleware and communication. Int. J. Wirel. Inf. Netw. 2020. [CrossRef]

12. Rodney, B. Understanding the paradigm shift in education in the twenty-first century. Worldw. Hosp. Tour. Themes 2020, 12, 35-47. [CrossRef]

13. Abdullah, A.; Hamad, R.; Abdulrahman, M.; Moala, H.; Elkhediri, S. CyberSecurity: A review of internet of things (IoT) security issues, challenges and techniques. In Proceedings of the 2019 2nd International Conference on Computer Applications Information Security, Riyadh, Saudi Arabia, 1-3 May 2019. [CrossRef]

14. Lu, Y.; Xu, L. Internet of things (IoT) cybersecurity research: A review of current research topics. IEEE Int. Things J. 2019, 6, 2103-2115. [CrossRef]

15. International Telecommunication Union (ITU). Recommendation ITU-T Y.2060. 2012. Available online: http://handle.itu.int/11.1002/1000/11559 (accessed on 19 April 2020).

16. Ashton, K. That 'internet of things' thing. RFID J. 2009, 22, 97-114.

17. Gabbai, A. Kevin Ashton Describes "The Internet of Things". 2015. Available online: https://www. smithsonianmag.com/innovation/kevin-ashton-describes-the-internet-of-things-180953749/ (accessed on 19 April 2020).

18. Songsom, N.; Nilsook, P.; Wannapiroon, P. The synthesis of the student relationship management system using the internet of things to collect the digital footprint for higher education institutions. Int. J. Online Biomed. Eng. 2019, 15, 99. [CrossRef]

19. Raman, A. Potentials of fog computing in higher education. Int. J. Emerg. Technol. Learn. 2019, 14, 194. [CrossRef]

20. Sengupta, S. Internet of Things: Applications in Education Sector. AJANTA 2019, 8, 24-27.

21. Chang, J.; Lin, W.; Chen, H. How attention level and cognitive style affect learning in a MOOC environment? Based on the perspective of brainwave analysis. Comput. Hum. Behav. 2019, 100, 209-217. [CrossRef]

22. Fernández-Caramés, T.; Fraga-Lamas, P. Towards next generation teaching, learning, and context-aware applications for higher education: A review on blockchain, IoT, fog and edge computing enabled smart campuses and universities. Appl. Sci. 2019, 9, 4479. [CrossRef]

23. Sun, G. Research on the cooperative development of university and industry economy based on internet of things technology. Trans. Emerg. Telecommun. Technol. 2020, e3917. [CrossRef]

24. Kuandee, W.; Nilsook, P.; Wannapiroon, P. Asset supply chain management system-based IoT technology for higher education institutions. Int. J. Online Biomed. Eng. 2019, 15, 4. [CrossRef]

25. Aldowah, H.; Ul Rehman, S.; Ghazal, S.; Naufal Umar, I. Internet of things in higher education: A study on future learning. J. Phys. Conf. Ser. 2017, 892, 012017. [CrossRef]

26. Tianbo, Z. The internet of things promoting higher education revolution. 2012 Fourth Int. Conf. Multimed. Inf. Netw. Secur. 2012. [CrossRef]

27. Militaru, G.; Simion, C.; Deselnicu, D.; Ioanid, A.; Niculescu, C. Examining students' acceptance of internet of things technology in higher education. In Proceedings of the 30th International Business-InformationManagement-Association Conference, Soliman, Madrid, Spain, 8-9 November 2017; pp. 3615-3623.

28. Abbasy, M.; Quesada, E. Predictable influence of IoT (internet of things) in the higher education. Int. J. Inf. Educ. Technol. 2017, 7, 914-920. [CrossRef]

29. Majeed, A.; Ali, M. How internet-of-things (IoT) making the university campuses smart? QA higher education (QAHE) perspective. In Proceedings of the 2018 IEEE 8th Annual Computing and Communication Workshop and Conference (CCWC), Las Vegas, NV, USA, 8-10 January 2018. [CrossRef] 
30. Soler, U.; Busilo, M. Education of society as a tool to counteract disinformation in implementing new technologies. On the example of 5G mobile telecommunications network and Warsaw sewage system. In Proceedings of the 2019 Applications of Electromagnetics in Modern Engineering and Medicine (PTZE), Janow Podlaski, Poland, 9-12 June 2019. [CrossRef]

31. Sysoieva, S.; Osadcha, K. Condition, technologies and prospects of distance learning in the higher education of Ukraine. Inf. Technol. Learn. Tools 2019, 70, 271. [CrossRef]

32. Bajracharya, B.; Blackford, C. Prospects of internet of things in education system. CTE J. 2018, 6, 1-7.

33. Conde-Zhingre, L.; Quezada-Sarmiento, P.; Labanda, M. The new generation of mobile networks: 5G technology and its application in the e-education context. In Proceedings of the 2018 13th Iberian Conference on Information Systems and Technologies (CISTI), Caceres, Spain, 13-16 June 2018. [CrossRef]

34. Baratè, A.; Haus, G.; Ludovico, L.; Pagani, E.; Scarabottolo, N. 5G technology and its applications to music education. In Proceedings of the International Conference On E-Learning, Athens, GA, USA, 20-22 July 2017. [CrossRef]

35. Dake, D.; Adjei, B. 5G enabled technologies for smart education. Int. J. Adv. Comput. Sci. Appl. $2019,10$. [CrossRef]

36. Amin, M.; Alamri, M.M.; Al-Rahmi, W. Applying the UTAUT model to explain the students' acceptance of mobile learning system in higher education. IEEE Access 2019, 7, 174673-174686. [CrossRef]

37. Arain, A.A.; Hussain, Z.; Rizvi, W.H.; Saleem, M. Extending UTAUT2 toward acceptance of mobile learning in the context of higher education. Univers. Access Inf. Soc. 2019, 18, 659-673. [CrossRef]

38. Martín, A.V.; García, A.; Muñoz, J.M. Determinants of blended learning adoption in higher education. Adaptation of the Utaut model. Educ. Xx1 2014, 17, 217-240. [CrossRef]

39. Prasad, P.W.C.; Maag, A.; Redestowicz, M.; Hoe, L.S. Unfamiliar technology: Reaction of international students to blended learning. Comput. Educ. 2018, 122, 92-103. [CrossRef]

40. Shinners, L.; Aggar, C.; Grace, S.; Smith, S. Exploring healthcare professionals' understanding and experiences of artificial intelligence technology use in the delivery of healthcare: An integrative review. Health Inf. J. 2019, 1460458219874641. [CrossRef] [PubMed]

41. Sohn, K.; Kwon, O. Technology acceptance theories and factors influencing artificial Intelligence-based intelligent products. Telemat. Inf. 2020, 47, 101324. [CrossRef]

42. Zhang, Z.L.; Cao, T.H.; Shu, J.B.; Liu, H. Identifying key factors affecting college students' adoption of the e-learning system in mandatory blended learning environments. Interact. Learn. Environ. 2020, in press. [CrossRef]

43. Venkatesh, V.; Morris, M.G.; Davis, G.B.; Davis, F.D. User acceptance of information technology: Toward a unified view. Mis Q. 2003, 27, 425-478. [CrossRef]

44. Venkatesh, V.; Thong, J.Y.; Xu, X. Consumer acceptance and use of information technology: Extending the unified theory of acceptance and use of technology. Mis Q. 2012, 36, 157-178. [CrossRef]

45. Fagan, M.H. Factors influencing student acceptance of mobile learning in higher education. Comput. Sch. 2019, 36, 105-121. [CrossRef]

46. Wei, J.; Vinnikova, A.; Lu, L.; Xu, J. Understanding and predicting the adoption of fitness mobile apps: Evidence from China. Health Commun. 2020, 1-12. [CrossRef]

47. Baishya, K.; Vardhan, H. Extending unified theory of acceptance and use of technology with perceived monetary value for smartphone adoption at the bottom of the pyramid. Int. J. Inf. Manag. 2020, 51, 102036. [CrossRef]

48. Song, C.; Woo, S.; Sohn, Y.W. Acceptance of public cloud storage services in South Korea: A multi-group analysis. Int. J. Inf. Manag. 2020, 51, 102035. [CrossRef]

49. Kissi, P.S.; Oluwatobiloba, M.K.; Berko, A.Y. Factors affecting university students intentions to use debit card services: an empirical study based on UTAUT. Bus. Manag. Educ. 2017, 15, 196-210. [CrossRef]

50. Nikolopoulou, K.; Gialamas, V.; Lavidas, K. Acceptance of mobile phone by university students for their studies: An investigation applying UTAUT2 model. Educ. Inf. Technol. 2020, in press. [CrossRef]

51. Yuan, Y.; Fulk, J.; Shumate, M.; Monge, P.R.; Bryant, J.A.; Matsaganis, M. Individual participation in organizational information commons: The impact of team level social influence and technology-specific competence. Hum. Commun. Res. 2005, 31, 212-240. [CrossRef]

52. Khechine, H.; Raymond, B.; Augier, M. The adoption of a social learning system: Intrinsic value in the UTAUT model. Br. J. Educ. Technol. 2020, in press. [CrossRef] 
53. Liu, L.; Su, X.; Akram, U.; Abrar, M. The user acceptance behavior to mobile digital libraries. Int. J. Enterp. Inf. Syst. 2020, 16, 1-16. [CrossRef]

54. Yan, P.; Bao, H.; Selvachandran, G.; Quynh, L.; Minh, H.T.; Hoang, L.; Abdel-Baset, M.; Manogaran, G.; Varatharajan, R. Perception, acceptance and willingness of older adults in Malaysia towards online shopping: A study using the UTAUT and IRT models. J. Ambient Intell. Hum. Comput. 2020, in press. [CrossRef]

55. Holzmann, P.; Schwarz, E.J.; Audretsch, D.B. Understanding the determinants of novel technology adoption among teachers: The case of 3D printing. J. Technol. Transf. 2020, 45, 259-275. [CrossRef]

56. Zhou, X.; Matsaganis, M. Toward reducing institutional digital divides in the media industry: Examining social media use in ethnic media organizations. Int. J. Commun. 2020, 14, 1004-1024.

57. World Health Organization. Life Course. 2017. Available online: https://www.who.int/elena/life_course/ (accessed on 19 April 2020).

58. Oviedo-Trespalacios, O.; Briant, O.; Kaye, S.A.; King, M. Assessing driver acceptance of technology that reduces mobile phone use while driving: The case of mobile phone applications. Accid. Anal. Prev. 2020, 135, 105348. [CrossRef]

59. Tam, C.; Santos, D.; Oliveira, T. Exploring the influential factors of continuance intention to use mobile Apps: Extending the expectation confirmation model. Inf. Syst. Front. 2020, 22, 243-257. [CrossRef]

60. Hair, J.F.; Hult, G.T.M.; Ringle, C.; Sarstedt, M. A Primer on Partial Least Squares Structural Equation Modeling (PLS-SEM), 2nd ed.; Sage: Thousand Oaks, CA, USA, 2017.

61. Ruiz, M.A.; Pardo, A.; San Martín, R. Structural equation models. Pap. Del Psicól. 2010, 31, 34-45.

62. Mardia, K.V. Measures of multivariate skewness and kurtosis with applications. Biometrika 1970, 57, 519-530. [CrossRef]

63. Cronbach, L.J. Coefficient alpha and the internal structure of tests. Psychometrika 1951, 16, 297-334. [CrossRef]

64. Ratchford, B.T. New insights about the FCB grid. J. Advert. Res. 1987, 27, 24-38.

65. Campbell, D.T.; Fiske, D.W. Convergent and discriminant validation by the multitreat-multimethod matrix. Psychol. Bull. 1959, 56, 81-105. [CrossRef]

66. Bollen, K.A. Structural Equations with Latent Variables; Wiley: New York, NY, USA, 1989.

(C) 2020 by the authors. Licensee MDPI, Basel, Switzerland. This article is an open access article distributed under the terms and conditions of the Creative Commons Attribution (CC BY) license (http://creativecommons.org/licenses/by/4.0/). 